\title{
The Structural Transformation and Aggregate Productivity in Portugal ${ }^{\dagger}$
}

\author{
Margarida Duarte \\ University of Toronto \\ Diego Restuccia \\ University of Toronto
}

November 2006

\begin{abstract}
We document the substantial process of structural transformation - the reallocation of labor between agriculture, manufacturing, and services - and aggregate productivity growth undergone by Portugal between 1956 and 1995. In this paper, we assess the quantitative role of sectoral productivity in accounting for these processes. We calibrate a model of the structural transformation to data for the United States and use the model to gain insight into the factors driving the structural transformation and aggregate productivity growth in Portugal. The model implies that Portugal features low and roughly constant relative productivity in agriculture and services (around 22 percent) and a modest but growing relative productivity in manufacturing (from 44 to 110 percent). We find that productivity growth in manufacturing accounts for most of the reduction of the aggregate productivity gap with the United States and that further substantial improvements in relative aggregate productivity can only be accomplished via improvements in the relative productivity of the service sector.
\end{abstract}

Keywords: productivity, structural transformation, relative sectoral productivity. JEL Classification: $01,04$.

†This paper was written while the authors were affiliated with the Federal Reserve Bank of Richmond. We would like to thank the editor, two anonymous referees, and participants at the Third Conference on Portuguese Economic Development in the European Context organized by the Bank of Portugal for their comments. All errors are our own. Contact Information: Department of Economics, University of Toronto, 150 St. George Street, Toronto, ON M5S 3G7, Canada.

E-mail: margarida.duarte@utoronto.ca and diego.restuccia@utoronto.ca. 


\section{Introduction}

We address the long-run economic performance of Portugal and its relation to the process of structural transformation. Between 1956 and 1995, Portugal reduced its aggregate labor productivity gap with the United States from 26 percent to 53 percent. ${ }^{1}$ During the same time period, Portugal underwent a substantial process of structural transformation, whereby the agricultural sector was replaced in importance in a first stage by the manufacturing sector and in a second stage by the service sector. In this paper, we assess the quantitative role of sectoral productivity differences in accounting for the substantial process of structural transformation in Portugal and aggregate productivity growth relative to that of the United States.

We develop a three-sector general-equilibrium model of the structural transformation following closely Rogerson (2005). In the model, labor reallocation across sectors is driven by two channels: income effects due to non-homothetic preferences as in Kongsamut, Rebelo, and Xie (2001) and substitution effects due to differential productivity growth across sectors as in Ngai and Pissarides (2004). We calibrate the benchmark economy to the structural transformation of the United States between 1956 and 1995. We first use the model to study the determinants of the process of structural transformation in Portugal during the same time period. We then assess the role of sectoral labor productivity growth in the process of structural transformation and in aggregate productivity in Portugal. ${ }^{2}$

We use the model calibrated to the U.S. experience to restrict the levels of sectoral labor

\footnotetext{
${ }^{1}$ We measure labor productivity as gross domestic product (GDP) per worker.

${ }^{2}$ The model allows us to isolate the contribution of sectoral productivity since shares of employment are endogenous to productivity changes.
} 
productivity in Portugal relative to that in the United States in 1956. We restrict these productivity differences so that the model is consistent with the observed employment shares by sector and the level of relative aggregate labor productivity in Portugal in this year. Together with the sectoral growth rates of labor productivity observed in the data between 1956 and 1995, we find that Portugal featured low and roughly constant relative productivity in agriculture and services (around 22 percent) and a modest but growing relative productivity in manufacturing (from 44 to 110 percent). In addition, Portugal featured a time-varying barrier to services. These features are essential in accounting for the process of structural transformation and the evolution of relative aggregate labor productivity in Portugal.

We then use the model of the structural transformation in Portugal to assess the quantitative role of sectoral labor productivity growth in the process of structural transformation and in relative aggregate labor productivity in Portugal. To do so, we perform a series of counterfactual experiments whereby we replace a given observed sectoral labor productivity growth rate with a hypothetical one. Each counterfactual experiment has implications for labor allocation across sectors and relative aggregate productivity. Our analysis suggests that productivity growth in manufacturing accounts for most of the reduction in the aggregate productivity gap with the United States between 1956 and 1995. Moreover, the model implies that improving labor productivity in the service sector would have large consequences for aggregate productivity in the context of the underlying structural transformation while leaving labor allocations roughly unchanged. In contrast, improving labor productivity in agriculture alone would have negligible effects on aggregate labor productivity while generating a substantial reallocation of labor out of agriculture. As a result, we find that when 
improvements in labor productivity in agriculture and services are combined, the reallocation of labor out of agriculture magnifies the aggregate productivity impact of labor productivity in services.

Our paper is broadly related to a recent literature studying the evolution of countries over time. $^{3}$ In linking the process of structural transformation with the evolution of aggregate productivity, our paper is closely related to the study of regional convergence in the United States by Caselli and Coleman (2001) and to the study of cross-country income differences by Gollin, Parente, and Rogerson (2002). Our study differs from these papers in that we consider three sectors of the economy and that we use the model to restrict sectoral productivity differences between Portugal and the United States. Our paper is also related to Cavalcanti (2004) who studies business cycles in Portugal and Duarte and Restuccia (2006) who study productivity differences across countries. Our focus in this paper is instead on the long-run evolution of Portugal.

The paper is organized as follows. In the next section we document the long-run performance of the Portuguese economy relative to the United States and the process of structural transformation in both countries. In section 3, we describe the model. We calibrate the model in section 4 and present the results in section 5 . We conclude in section 6 .

\footnotetext{
${ }^{3}$ See, for instance, Cole and Ohanian (1999) and Kehoe and Prescott (2002).
} 


\section{Transformation and Long-run Performance}

In this section, we document the economic performance and the process of structural transformation in Portugal relative to the United States from 1950 to 2000. ${ }^{4}$ We focus on labor productivity (GDP per worker) as our measure of economic performance and document the behavior of GDP per worker in Portugal relative to that of the United States. ${ }^{5}$

\subsection{The Behavior of Aggregate Labor Productivity}

We find a substantial process of convergence in aggregate labor productivity in Portugal relative to the United States from 1950 until the mid 1970's. However, this process slowed down considerably in the mid 1970's. (See Figure 1.) Relative aggregate labor productivity in Portugal increased steadily between 1950 to 1975, from about 0.22 to 0.45 . Between 1975 and 2000, relative GDP per worker in Portugal grew only 10 percentage points (from 0.45 to 0.55$){ }^{6}$

To gain insight about the driving forces behind movements in output per worker we consider an aggregate production function that is common to both countries. Let output $Y$ in a given country be characterized by a Cobb-Douglas production function that depends on the total capital stock $K$, total hours worked $L h$, and total factor productivity (TFP) $A$ :

$$
Y=A K^{\alpha}(L h)^{1-\alpha}
$$

\footnotetext{
${ }^{4}$ Later on in the paper we compare the long-run performance of Portugal relative to that of the United States from 1956 to 1995 due to data restrictions on sectoral employment.

${ }^{5}$ We focus on trended data, obtained by applying the Hodrick-Prescott filter with smoothing parameter $\lambda=100$.

${ }^{6}$ Relative aggregate labor productivity in Portugal was 0.26 in 1956 and 0.53 in 1995.
} 
In this expression, $L$ represents the number of workers employed, $h$ represents average hours worked per employed person, and $\alpha$ represents the share of payments to capital in total income $Y$ (when factor markets are competitive). Given observations on the capital stock, employment, hours worked, and output and given an estimate for the share of payments to capital in total income, we can obtain a measure of TFP (which is not directly observable in the data) as the residual in equation (1).

We use equation (1) to write output per worker $Y / L$ in its intensive form as:

$$
\frac{Y}{L}=A^{\frac{1}{1-\alpha}}\left(\frac{K}{Y}\right)^{\frac{\alpha}{1-\alpha}} h .
$$

This equation shows that movements in GDP per worker $Y / L$ can be decomposed into movements in measured TFP, movements in the capital to output ratio $K / Y$, and movements in the average number of hours worked $h$.

Empirical evidence suggests that capital to output ratios are remarkably stable over time for many countries, including the United States and Portugal. ${ }^{7}$ As a result, we abstract from movements in the capital to output ratio as a driving force of relative GDP per worker between Portugal and the United States. In this section, we focus on the contribution of relative movements in measured TFP and hours worked in Portugal and the United States. ${ }^{8}$

In the United States, average hours worked per year fell from 2,008 hours (about 39 hours per week) in 1950 to 1,878 (about 36 hours per week) in 2000. Thus, movements

\footnotetext{
${ }^{7}$ See, for instance, Kaldor (1961), Cooley and Prescott (1995), Kongsamut, Rebelo, and Xie (2001) for the United States and Cavalcanti (2004) for Portugal.

${ }^{8}$ We use data on hours per worker from the Conference Board and Groningen Growth and Development Centre (2005), Total Economy Database.
} 
in hours worked contributed negatively towards growth in GDP per worker in this period. In Portugal, average hours worked fell by more than in the United States between 1950 and 2000. Average hours worked were 2,344 (about 45 hours per week) in 1950 and they fell to 1,715 by 2000 (about 33 hours per week). As a result, the pattern of hours worked in Portugal relative to that of the United States suggests that hours worked contributed negatively towards the observed convergence of relative GDP per worker.

Given the behavior of hours worked in Portugal relative to that of the United States over the period, we conclude that movements in productivity (measured TFP) were the main driving force behind the increase in relative GDP per worker in Portugal (which more than offset the fall in relative hours worked). We use this evidence to develop a model in Section 3 that emphasizes the role of sectoral productivity on aggregate labor productivity. While there are many potential sources of relative productivity movements across sectors (for instance, reallocation of capital, human capital and occupational choice, among others), we abstract from these channels and focus attention on the implications of sectoral productivity on the allocation of employment across sectors and aggregate productivity.

\subsection{The Process of Structural Transformation}

The behavior of relative labor productivity in Portugal depicted in Figure 1 is associated with different patterns of labor productivity across sectors as well as a substantial process

of labor reallocation. This reallocation process from agriculture to manufacturing and from manufacturing into the service sector is typically referred to in the development literature 
as the structural transformation of the economy. ${ }^{9}$

The process of structural transformation has been extensively documented in the literature. ${ }^{10}$ This process is typically characterized by a substantial fall in the share of employment in agriculture to less than 10 percent, by a steady increase in the share of employment in services, and by a hump-shaped pattern in the share of employment in manufacturing. That is, the typical process of structural transformation involves an increase in the share of employment in manufacturing in the early stages, followed by a decrease in the later stages.

Different economies have started the process of structural transformation at different points in time. In Figure 2 we report the shares of employment in agriculture, manufacturing, and services in the United States from 1869 to 1970, which are broadly consistent with the general characterization described above. By the middle of the $20^{\text {th }}$ century, a substantial degree of sectoral labor reallocation had already taken place in the United States. While in 1869 the share of employment in agriculture, manufacturing, and services were $0.48,0.24$, and 0.28 , by 1948 these shares were $0.10,0.34$, and 0.56 . In the second half of the century, the process of labor reallocation from agriculture and manufacturing into services continued (see first panel in Figure 3). From 1956 to 1995, the share of employment in agriculture in the United States fell from about 10 percent to about 3 percent, the share of employment in manufacturing fell from about 36 percent to 24 percent, while the share of employment in services increased from 54 percent to 73 percent. ${ }^{11}$

\footnotetext{
${ }^{9}$ In this paper we refer to manufacturing and industry interchangeably. In the appendix we describe in detail our definition of sectors in the data.

${ }^{10}$ See, for instance, Kuznets (1966), Maddison (1980), among others.

${ }^{11}$ Figure 2 and the first panel in Figure 3 use different data sources and the shares of employment for 1956 do not match. Nevertheless, the two figures are consistent regarding the pattern of structural transformation in the United States.
} 
Portugal has experienced a process of structural transformation that is broadly consistent with the experience of other economies. Figure 3 (second panel) documents the share of employment in agriculture, manufacturing, and services for Portugal from 1956 to 1995. Portugal has undergone a substantial process of sectoral labor reallocation in the last 50 years. The share of employment in agriculture has fallen from 48 percent in 1956 to 12 percent in 1995. The share of employment in the service sector has increased steadily throughout this period, from 33 percent in 1956 to 65 percent in 1995. Similarly to other countries, the share of employment in manufacturing during this period has a hump-shaped pattern - it increased from 1956 to 1980 (from 19 percent to 26 percent) and decreased thereafter (to 23 percent in 1995). It is interesting to note that the structural transformation in Portugal from 1956 to 1995 resembles closely that of the United States between 1870 and 1956. Although Portugal started the process of structural transformation later than the United States, it has accomplished about the same reallocation of labor across sectors in less than half the time (39 years in Portugal versus 89 years in the United States).

The evolution of employment across sectors observed in Portugal and the United States between 1956 and 1995 is associated with distinct patterns of labor productivity across sectors. In the United States, labor productivity increased in all sectors, specially so in agriculture, as shown in the third panel in Figure 3. The annualized growth rates of labor productivity between 1956 and 1995 were 3.8 percent in agriculture, 2.4 percent in manufacturing, and 1.5 percent in services. Sectoral labor productivity in Portugal between 1956 and 1995 is shown in the fourth panel of Figure 3. The annualized growth rates of labor productivity over this period were 4.8 percent in manufacturing, 4.1 percent in agriculture, 
and 1.9 percent in services.

From an accounting perspective, the patterns of labor productivity and share of employment across sectors determine the behavior of aggregate labor productivity. Since the shares of employment are endogenous to labor productivity across sectors, in the following sections we develop a general equilibrium model of the structural transformation and calibrate it to the U.S. experience. We use the calibrated model to asses the role of each sector in the process of structural transformation and relative aggregate productivity in Portugal.

\section{The Model}

We consider a simple model of the structural transformation of an economy as in Duarte and Restuccia (2006). The model follows closely Rogerson (2005). At each date three goods are produced: agriculture, manufacturing, and services. In the model, there are two sources of structural transformation: non-homothetic preferences and an elasticity of substitution between consumption of manufacturing and service goods different from one.

\subsection{Description of Economic Environment}

Production At each date there are three goods produced: agriculture $(a)$, manufacturing $(m)$, and services $(s)$ according to the following constant returns to scale production functions:

$$
Y_{i}=A_{i} L_{i}, \quad i \in\{a, m, s\},
$$


where $Y_{i}$ is output in sector $i, L_{i}$ is labor allocated to production in sector $i$, and $A_{i}$ is a sector-specific technology parameter.

Households The economy is populated by an infinitely-lived representative household of constant size over time. (Without loss of generality we normalize the population size to one.) We assume that the household is endowed with one unit of productive time each period that is supplied inelastically to the market. The household has preferences over consumption goods as follows:

$$
\sum_{t=0}^{\infty} \beta^{t} u\left(c_{t}, c_{a, t}\right), \quad \beta \in(0,1)
$$

where $c_{a, t}$ is the consumption of agricultural goods at date $t$ and $c_{t}$ is the consumption of a composite of manufacturing and service goods at date $t$. The per-period utility is given by:

$$
u\left(c_{t}, c_{a, t}\right)=\log \left(c_{t}\right)+V\left(c_{a, t}\right)
$$

where $V\left(c_{a, t}\right)$ is such that households only care to consume a subsistence level of agricultural goods $\bar{a} .{ }^{12}$ Formally, $V\left(c_{a}\right)=-\infty$ when $c_{a}<\bar{a}$, and $V\left(c_{a}\right)=\min \left\{c_{a}, \bar{a}\right\}$ when $c_{a} \geq \bar{a}$. This specification of preferences $V$ makes our analysis much more tractable. We show in Section 5 that this simple preference specification captures the agricultural share of employment in the data remarkably well.

\footnotetext{
${ }^{12}$ The specification of preferences for agricultural goods featuring a subsistence level - i.e., a level of consumption below which the household cannot survive - has a long tradition in the development literature. See, for instance, Echevarria (1997), Laitner (2000), Kongsamut, Rebelo, and Xie (2001), Caselli and Coleman (2001), Gollin, Parente, and Rogerson (2002), Restuccia, Yang, and Zhu (2005), Ngai and Pissarides (2004), among many others. We follow Laitner (2000) and Gollin, Parente, and Rogerson (2002) in further simplifying the specification of preferences for agriculture by assuming that households only care to consume the subsistence level $\bar{a}$.
} 
The composite consumption $c_{t}$ is given by:

$$
c_{t}=\left[b c_{m, t}^{\rho}+(1-b)\left(c_{s, t}+\bar{s}\right)^{\rho}\right]^{\frac{1}{\rho}},
$$

where $\bar{s}>0, b \in(0,1)$, and $\rho<1$. Given $\bar{s}$, these preferences imply that the income elasticity of consumption of service goods is greater than one. The parameter $\bar{s}$ can be interpreted as a constant level of production of service goods at home. Rogerson (2005) considers a generalization of this feature where people can allocate time to market and non-market production of service goods. However, we argue that our simplification is not as restrictive as it may first appear since we abstract from labor hours in the model.

Market Structure We assume that there is a continuum of representative firms in each sector that are competitive in output and factor markets. At each date, given the price of good- $i$ output $p_{i}$ and wages $w$, a representative firm in sector $i$ solves:

$$
\max _{L_{i} \geq 0} p_{i} A_{i} L i-w L_{i}
$$

where $L_{i}$ is the demand of labor in sector $i$.

The problem of the household is also static. At each date and given prices, the household chooses consumption of each good to maximize the per-period utility subject to the budget constraint. Formally,

$$
\max _{c_{i} \geq 0} \log \left[b c_{m}^{\rho}+(1-b)\left(c_{s}+\bar{s}\right)^{\rho}\right]^{\frac{1}{\rho}}+V\left(c_{a}\right),
$$


subject to

$$
p_{a} c_{a}+p_{m} c_{m}+p_{s} c_{s}=w
$$

In what follows we normalize the wage rate to one.

Market Clearing The demand of labor from firms must equal the exogenous supply of labor at every date:

$$
L_{a}+L_{m}+L_{s}=1
$$

Notice that labor inputs in the model $L_{i}$ can be associated with the shares of employment in the data. In addition, at each date the market for each good produced must clear:

$$
c_{a}=Y_{a}, \quad c_{m}=Y_{m}, \quad c_{s}=Y_{s}
$$

\subsection{Equilibrium of the Model}

A competitive equilibrium is a set of prices $\left\{p_{a}, p_{m}, p_{s}\right\}$, allocations $\left\{c_{a}, c_{m}, c_{s}\right\}$ for the household, and allocations $\left\{L_{a}, L_{m}, L_{s}\right\}$ for firms such that: (i) Given prices, firm's allocations $\left\{L_{a}, L_{m}, L_{s}\right\}$ solve the firm's problem in (4), (ii) Given prices, household's allocations $\left\{c_{a}, c_{m}, c_{s}\right\}$ solve the household's problem in (5), and (iii) markets clear: equations (6) and (7) hold.

The first order condition from the firm's problem implies that the benefit and cost of a marginal unit of labor must be equal. Since the wage rate is normalized to one, it follows 
that prices of goods are inversely related to productivity:

$$
p_{i}=\frac{1}{A_{i}}
$$

Our specification of $V\left(c_{a}\right)$ implies that $c_{a}=\bar{a}$ and, therefore, labor in agriculture must satisfy:

$$
L_{a}=\frac{\bar{a}}{A_{a}}
$$

The first order conditions for consumption of manufacturing and service goods imply:

$$
\frac{b}{(1-b)}\left(\frac{c_{m}}{c_{s}+\bar{s}}\right)^{\rho-1}=\frac{p_{m}}{p_{s}} .
$$

Using the market clearing conditions for output in manufacturing and services and for labor we obtain:

$$
L_{m}=\frac{\left(1-L_{a}\right)+\frac{\bar{s}}{A_{s}}}{1+x}
$$

where

$$
x \equiv\left(\frac{b}{1-b}\right)^{\frac{1}{\rho-1}}\left(\frac{A_{m}}{A_{s}}\right)^{\frac{\rho}{\rho-1}}
$$

and $L_{a}$ is given by (8).

Notice that when $\bar{s}=0$, equation (9) can be written as $L_{s} / L_{m}=x$. If, in addition, $\rho=0$, then the composite consumption good $c$ is a Cobb-Douglas aggregate of consumption of manufacturing and service goods and differential productivity growth across these two sectors will cause no reallocation of labor. The elasticity of substitution between manufacturing and 
service goods $\rho$ determines how much relative labor productivity growth $A_{m} / A_{s}$ is needed to produce a given reallocation of labor across sectors, for given $\bar{s} / A_{s}$. For $\bar{s}=0$, the model is consistent with labor reallocation from manufacturing into services as labor productivity grows in the manufacturing sector relative to services if $\rho<0$. When $\bar{s}$ is strictly positive, however, the model implies a given amount of labor reallocation from manufacturing into services as labor productivity in services grows for higher elasticity of substitution $\rho$.

\section{Calibration}

We calibrate the benchmark economy to U.S. data for the period from 1956 to 1995. Our calibration strategy involves selecting parameter values so that the equilibrium of the model matches a given set of statistics in the data. We show that our simple framework captures the salient features of the structural transformation in the United States in this period.

\subsection{Description}

We assume that a model period is one year. We need to select the following parameters values: $b, \rho, \bar{a}, \bar{s}$, and the time series of productivity for each sector $A_{i, t} i \in\{a, m, s\}$ for $t$ from 1956 to 1995 . Table 1 reports a summary of calibrated parameters and targets.

Our calibration strategy is to restrict the parameters values to match the structural transformation of the United States between 1956 and 1995. Since in the model labor allocation in agriculture is determined independently of the state of the other sectors, the calibration procedure can be roughly divided in two parts. First, we calibrate subsistence 
Table 1: Parameter Values and Targets

\begin{tabular}{ccl}
\hline Parameter & Value & Target U.S. Data \\
\hline$A_{i, 56}$ & 1.0 & Normalization \\
$\left\{A_{a, t}\right\}_{t=57}^{55}$ & $\{\cdot\}$ & Labor Productivity Growth Agriculture \\
$\left\{A_{m, t}\right\}_{t=57}^{95}$ & $\{\cdot\}$ & Labor Productivity Growth Industry \\
$\left\{A_{s, t}\right\}_{t=57}^{55}$ & $\{\cdot\}$ & Labor Productivity Growth Services \\
$\bar{a}$ & 0.10 & Employment in Agriculture 1956 \\
$\bar{s}$ & 0.76 & Employment in Industry 1956 \\
$b$ & 0.04 & Employment in Industry 1957-1995 \\
$\rho$ & -1.5 & Aggregate Labor Productivity Growth \\
\hline
\end{tabular}

in agriculture so that the equilibrium of the model matches the share of employment in agriculture for 1956. Second, we calibrate the other parameters of the model to match the share of employment in manufacturing and aggregate productivity growth.

We proceed as follows. First, we normalize productivity levels across sectors to one in 1956, i.e., $A_{i, 56}=1$ for $i \in\{a, m, s\}$. Second, given our normalization of productivity in 1956, we use data on labor productivity growth in the United States for each sector to obtain the time paths of productivity levels. ${ }^{13}$ Third, given the normalization $A_{a, 56}=1$, we choose $\bar{a}$ to obtain the share of employment in agriculture in 1956 for the United States (see equation (8)). Given the calibrated value for subsistence in agriculture, labor productivity growth in this sector implies a share of employment in agriculture in the model that turns out to be remarkably close to the time-series data for the United States. (See Figure 4.)

In the second component of the calibration, we restrict $\bar{s}, b$, and $\rho$ to match the share of employment in manufacturing over time and the annualized growth rate of aggregate labor

\footnotetext{
${ }^{13}$ The annualized growth rates of labor productivity between 1956 and 1995 for the United States are 3.8, 2.4 and 1.5 percent for agriculture, industry and services. Annualized growth rates between 1956 and 1995 are computed as $\gamma_{A_{i}}=\left(\frac{A_{i, 95}}{A_{i, 56}}\right)^{1 / 39}-1$.
} 
productivity. We proceed as follows. Given $\rho$ and $b, \bar{s}$ is chosen to match the share of employment in manufacturing for the United States in 1956. Then $b$ is chosen so that, given the time paths for labor productivity in manufacturing and services, the model matches the time path for the share of employment in manufacturing. Since $\rho$ determines how much relative productivity growth is needed to produce a given reallocation of labor across sectors, $\rho$ induces different patterns of aggregate productivity growth. We choose $\rho$ to match average aggregate productivity growth during the period (at 1956 prices). We calculate from PWT6.1 that the annualized growth rate of labor productivity in the United States between 1956 and 1995 is 1.8 percent.

\subsection{Results of the Benchmark Economy}

Our calibration restricted preference and technology parameters of the model to match some features of the data for the U.S. structural transformation between 1956 and 1995 . The shares of employment implied by the model are reported in Figure 4 (dotted lines), together with data for the United States (solid lines). The equilibrium shares of employment across sectors implied by the model match closely the process of structural transformation of the United States over this period. In particular, notice that although not explicitly calibrated, the model matches well the time path for the share of employment in agriculture. Also, the model implies a fall in the share of employment in manufacturing from about 38 percent in 1956 to 26 percent in 1995, while the share of employment in services increases from about 53 percent to 72 percent. We found that, given the observed sectoral growth rates of labor productivity in the United States, this process of labor reallocation between manufacturing 
and services could not be accomplished in the model without an income elasticity greater than one in services. ${ }^{14}$

\section{Quantitative Analysis}

The calibrated benchmark economy puts discipline on technology and preference parameters. In this section, we use the model calibrated to the United States to perform experiments aimed at gaining insight into sectoral productivity differences between Portugal and the United States and the process of structural transformation in Portugal. We then perform counterfactual exercises to assess the aggregate implications of different factors driving the process of structural transformation in Portugal. Our main findings are that between 1956 and 1995 Portugal featured low and constant relative labor productivity in agriculture and services, and low but growing relative productivity in manufacturing. Moreover, we show that, during the period, productivity growth in manufacturing accounts for a large portion of the reduction in the aggregate productivity gap with the United States. Moreover, the lack of relative productivity growth in services has kept Portugal lagging behind in aggregate productivity relative to the United States.

\footnotetext{
${ }^{14}$ Alternatively, if we interpret $\bar{s}$ as being produced with a home technology, then we would require a pattern for productivity growth in the home sector that depends on whether technological progress is labor augmenting or labor saving. See the discussion in Rogerson (2005) and the different approaches in Kongsamut, Rebelo, and Xie (2001) and Ngai and Pissarides (2004).
} 


\subsection{Structural Transformation in Portugal}

We take four steps aimed at understanding the structural transformation in Portugal. First, we consider an economy identical to the benchmark economy in terms of preferences but featuring a lower initial level of economy-wide productivity, consistent with the observation that output per worker in Portugal was 26 percent of the U.S. level in 1956. Second, we allow for relative productivity differences across sectors in 1956 that are consistent with the observed shares of employment in Portugal in this year. Third, we consider an economy in which, in addition to the features described above, productivity growth across sectors is driven by observations on sectoral productivity in Portugal. Finally, we consider a time-varying barrier to the productivity of services that allows us to match the share of employment in manufacturing in Portugal. In all these experiments, the parameter value for $\bar{s}$ is adjusted to the initial value of relative productivity in services for Portugal. ${ }^{15}$

Economy-wide Productivity The first experiment involves reducing labor productivity in every sector in 1956 by a constant factor. As documented in Section 2, GDP per worker in Portugal in 1956 was 26 percent of GDP per worker in the United States. Hence, this experiment assumes that relative labor productivity in each sector was 26 percent, i.e., $A_{i, 56}=0.26$ for $i \in\{a, m, s\} .{ }^{16}$ For 1956, the model implies a share of employment in agriculture of 39 percent (48 percent in the data), a share of employment in services of 31

\footnotetext{
${ }^{15}$ Although not explicitly modeled, one interpretation of $\bar{s}$ is as service goods produced at home. As a result, $\bar{s}$ cannot be invariant to large changes in productivity levels, such as those implied by the analysis of the United States and Portugal.

${ }^{16}$ We measure aggregate output in Portugal in any given year by summing sectoral outputs in that year measured at the sectoral prices of the benchmark economy in 1956.
} 
percent (33 percent in the data), and a share of employment in industry of 30 percent (19 percent in the data). Hence, the model implies too little employment in agriculture and services and too much employment in manufacturing relative to the data in 1956 . These results suggest that Portugal may be less than 26 percent productive in agriculture and more than 26 percent productive in manufacturing in 1956 relative to the United States. We pursue this possibility in the next experiment.

Relative Sectoral Productivity in 1956 We set relative sectoral productivity in 1956 so that the model matches the shares of employment across sectors in Portugal for the same year (in addition to the relative aggregate productivity of 26 percent). Our calibration of this experiment implies that agriculture, manufacturing, and services must be 22, 44, and 22 percent as productive as in the benchmark economy in $1956 .{ }^{17}$ The results of this experiment in terms of the shares of employment across sectors are reported in Panel A of Figure 5 where the solid lines represent the data and the dashed lines the model. Notice that the time path of the shares of employment are different than in the data, specially in manufacturing and industry.

\footnotetext{
${ }^{17}$ Recall from Figure 2 and the second panel of Figure 3 that Portugal underwent a structural transformation in agriculture between 1956 and 1995 that resembles closely the structural transformation of the United States between 1870 and 1956. Hence, an alternative calibration of $\bar{a}$ would be to match the share of employment in agriculture of the United States in 1870. Normalizing the productivity level of agriculture in 1870 to one, this alternative calibration would imply that $\bar{a}=0.48$. The level of relative productivity in agriculture in 1956 required to match the share of employment in this sector would be 4.8 or an annualized growth rate of productivity in agriculture of 1.84 percent. Note that this growth rate is less than half the observed growth rate of U.S. productivity in agriculture between 1956 and 1995. If this level of productivity represents the frontier in the world, then Portugal in 1956 should have observed a share of employment in agriculture of 10 percent as opposed to the 48 percent in the data. We conclude that Portugal is not riding along the same technological process as the United States. There are factors (either institutional or policy driven) that lead to a large share of employment in agriculture in Portugal in 1956.
} 
Sectoral Productivity Growth Portugal is not riding along the same technological process as the United States. While in 1956 relative sectoral productivity in Portugal were all below the U.S. level, Portugal experienced higher annualized rates of labor productivity growth in all three sectors. In this experiment, we use the growth rates of labor productivity in agriculture, manufacturing, and services observed in Portugal between 1956 and 1995, together with the features of the two previous experiments. The shares of employment implied by the model are plotted in Panel B of Figure 5. The share of employment in agriculture implied by the model matches very closely the data. This result suggests that the simple characterization of preferences for agricultural goods in the model represents a good abstraction of the forces for employment in agriculture relative to the data. The share of employment in services implied by the model grows faster than in the data, while the opposite occurs for the share of employment in manufacturing. We conclude that there may be factors preventing the movement of people from manufacturing to services. We consider as our next step a barrier to the service sector summarizing all the possible forces that prevent reallocation to services. ${ }^{18}$

Barriers to Services The previous discussion implies that our simple framework does not capture the process of labor reallocation between manufacturing and services observed in Portugal between 1956 and 1995. In this experiment, we add a time-varying barrier to the service sector so that the model matches the Portuguese structural transformation in this period. In particular, we assume that the barrier to services $\pi_{s} \geq 0$ affects wages in

\footnotetext{
${ }^{18}$ For instance, Prescott (2004) and Rogerson (2005) argue that taxes on market activities may be behind the employment problem in European countries.
} 
this sector $\frac{w_{s}}{\pi_{s}}$. Hence, from equation (9), we compute this barrier to match the share of employment in manufacturing as:

$$
\pi_{s}=\frac{\left[L_{m}(1+x)-\left(1-L_{a}\right)\right] A_{s}}{\bar{s}} .
$$

The results of this experiment are reported in Panel $\mathrm{C}$ of Figure 5. The resulting time-varying barrier to services has the feature that it grows almost monotonically from 1 in 1956 to 5 in 1995. The barrier can be interpreted as an increasing impact of taxes and other regulations in the service sector. ${ }^{19}$ Our benchmark economy with lower relative sectoral productivity in 1956, faster productivity growth, and a time-varying barrier to services is able to reproduce closely the pattern of labor reallocation observed for Portugal between 1956 and 1995. We use this economy as the basis of counterfactual experiments in the next subsection. ${ }^{20}$

Implications for Relative Sectoral Productivity The model implies levels of sectoral labor productivity relative to that of the United States that are consistent with aggregate data. These relative sectoral productivity are plotted in Figure 6. The model implies that labor productivity in manufacturing in Portugal converged fast relative to that of the United States during this period, from 0.44 in 1956 to 1.1 in 1995. Labor productivity in agriculture and services in Portugal, however, experienced very limited relative improvement during this

\footnotetext{
${ }^{19}$ See, for instance, Silva (2005) for evidence on increasing tax rates on consumption and labor in Portugal between 1970 and 2002.

${ }^{20}$ While the barrier to services is important to account for some features of the structural transformation in Portugal, we emphasize that the barrier is not quantitatively important for aggregate productivity in Portugal relative to the United States. Recall from Panel B in Figure 5 that, in the absence of this barrier, employment would move faster out of manufacturing into services. Since manufacturing in Portugal is relatively more productive than services, aggregate productivity growth would be lower in this counterfactual situation than with the barrier.
} 
period: in 1956 relative productivity in agriculture and services were 0.22 and by 1995 they were 0.25 and $0.26 .^{21}$

\subsection{Counterfactuals}

Our previous analysis suggests that productivity in agriculture and services in Portugal are behind the aggregate productivity gap with United States. In this subsection, we use the model to isolate the importance of productivity in each sector for the process of structural transformation and the evolution of aggregate productivity in Portugal.

(1) The role of Manufacturing In this counterfactual we ask about the role of productivity growth in manufacturing in explaining the catch up in relative aggregate productivity in Portugal between 1956 and 1995. We start from the economy that reproduces the structural transformation in Portugal and ask how this economy would change if labor productivity in manufacturing followed the path observed in the United States (an annualized growth rate of 2.4 percent per year instead of 4.8 percent in Portugal). Notice that this counterfactual situation would imply that relative labor productivity in manufacturing is constant at 44 percent during the time period. The results of this counterfactual are reported in Figure 7 (dashed line) and column (1) of Table 2. For comparison, in this table we also report the economy that reproduces the structural transformation for Portugal. A lower than observed productivity growth in manufacturing would imply more labor in manufacturing and less in services than observed in 1995. More importantly, relative aggregate productivity would be

\footnotetext{
${ }^{21}$ Notice that the model imposes discipline on the relative sectoral productivity levels in 1956 . Their evolution thereafter is implied by data on productivity growth by sector in each country.
} 
0.38 in 1995 instead of the 0.53 observed (an annualized growth of 2.8 percent instead of 3.7 percent). We conclude that high labor productivity growth in manufacturing accounts for most of the aggregate productivity growth in Portugal relative to that of the United States.

Table 2: Counterfactuals

\begin{tabular}{lccccc}
\hline & & $(1)$ & $(2)$ & $(3)$ & $(4)$ \\
& $\begin{array}{c}\text { Model } \\
\text { PT }\end{array}$ & $\begin{array}{c}\text { Prod. } \\
\text { Industry }\end{array}$ & $\begin{array}{c}\text { Prod. } \\
\text { Agriculture }\end{array}$ & $\begin{array}{c}\text { Prod. } \\
\text { Services }\end{array}$ & $\begin{array}{c}\text { Prod. } \\
\text { Ag. \& Svc. }\end{array}$ \\
\hline Labor productivity growth (\%): & & & & & \\
$\quad$ Agriculture & 4.1 & 4.1 & 7.8 & 4.1 & 7.8 \\
$\quad$ Industry & 4.8 & 2.4 & 4.8 & 4.8 & 4.8 \\
$\quad$ Services & 1.9 & 1.9 & 1.9 & 5.2 & 5.2 \\
Share of Employment 1995 (\%): & & & & & \\
$\quad$ Agriculture & 9.8 & 9.8 & 2.5 & 9.8 & 2.5 \\
$\quad$ Industry & 23.4 & 38.1 & 24.1 & 23.7 & 24.9 \\
$\quad$ Services & 66.8 & 52.1 & 73.4 & 66.5 & 72.6 \\
Aggregate Prod. (PT/US): & & & & & \\
$\quad$ 1956 & 0.26 & 0.26 & 0.26 & 0.26 & 0.26 \\
$\quad$ 1995 & 0.53 & 0.38 & 0.54 & 0.89 & 0.95 \\
Agg. Prod. Growth (\%) & 3.7 & 2.8 & 3.8 & 5.1 & 5.3 \\
\hline
\end{tabular}

(2) Closing the Productivity Gap in Agriculture The model implies that relative productivity in agriculture in Portugal was 22 percent in 1956 and 25 percent in 1995 . In contrast, Rogerson (2005) suggests that the productivity gap in agriculture between Europe (the average of the largest four countries) and the United States required to reproduce relative labor allocations in this sector in 2000 was 0.97 . We ask what the aggregate productivity implications would be of Portugal closing the productivity gap in agriculture to 0.97 by 1995. To produce this catch up, labor productivity in agriculture in Portugal would need to grow at an annual rate of 7.8 percent instead of the 4.1 percent observed in the data. The implied shares of employment and relative aggregate productivity are summarized in column 
(2) of Table 2. (See also Figure 7.) Closing the productivity gap in agriculture produces an important reallocation of employment from agriculture to services: by 1995, the share of employment changes from 10.5 to 2.5 percent in agriculture and from 67 to 73 percent in services. Nevertheless, the aggregate productivity implications of this change are relatively small: the annualized growth rate of aggregate productivity would increase to 3.8 percent (compared to 3.7 percent in the data for Portugal) and relative aggregate productivity would only increase to 0.54 (compared to 0.53 in the data). The intuition behind this result is that while improving productivity in agriculture produces an important reallocation of labor, this reallocation shifts labor mostly towards services. As we documented previously, agriculture and services in Portugal have roughly similar relative productivity. In addition, the direct effect of the sharp improvement in agricultural productivity in the aggregate falls over time, as the associated fall in the share of employment in agriculture reduces the weight of this sector in the aggregate economy.

(3) Closing the Productivity Gap in Services The model implies that productivity of services in Portugal relative to that of the United States was 22 percent in 1956 and 26 percent in 1995. In contrast, Rogerson (2005) suggests that the productivity gap in services between Europe and the United States required to reproduce relative labor allocations in 2000 is 0.89 . We ask about the implications for employment allocations and aggregate productivity of a change in relative productivity in services from 22 percent in 1956 to 89 percent in 1995. This remarkable change in relative productivity generates almost no effect in the shares of employment across sectors. The reason is that this improvement in 
productivity generates no effect in the allocation of labor in agriculture and two opposing effects in the allocation of labor across industry and services. First, higher productivity in services relative to manufacturing, all else equal, reallocates labor towards manufacturing due to the low substitutability between these two goods in preferences $(\rho<0)$. Second, higher productivity in the production of services relative to a constant $\bar{s}$, all else equal, reallocates labor towards services. In this counterfactual, these two opposing effects roughly cancel each other and the effects on labor allocations are small. However, the productivity change has an important effect in aggregate productivity because the improvement in productivity occurs in a large and growing sector of the economy (the structural transformation). The growth rate in aggregate productivity increases to 5.1 percent annually, leading to a relative aggregate productivity of 0.89 in 1995 as documented in the dotted line in Figure 7.

(4) Closing the Productivity Gap in Agriculture and Services We found that improving agricultural productivity by itself did not have large aggregate productivity effects in Portugal because it reallocated labor to a sector with similar relative productivity. However, when combined with improvements in the productivity of the service sector, the reallocation of labor implied by improving productivity in agriculture can amplify the aggregate productivity effects. In this counterfactual, we combine the improvements in productivity described in the previous two counterfactuals. As documented in Table 2, column (4), higher productivity in agriculture implies that there is a substantial release of labor from agriculture to services (as in the second counterfactual). In turn, higher relative productivity in services implies that this reallocation of labor has a higher aggregate effect than in the third 
counterfactual. Relative aggregate productivity in 1995 is 0.95 compared to 0.89 in the case of improvement in the service sector only. (See Figure 7.)

Discussion While manufacturing productivity accounts for most of the aggregate productivity growth in Portugal relative to that of the United States during the period, its role in determining aggregate productivity in the future is mitigated by its decreasing share in employment. (Recall that Portugal has already started a second phase of structural transformation whereby employment is moving from manufacturing to services.) Only relative productivity growth in services can effectively provide further closing of the aggregate productivity gap with the United States. As a result, our analysis suggests that finding ways of improving labor productivity in the service sector would have large consequences for aggregate productivity in the context of the underlying structural transformation. ${ }^{22}$

\section{Conclusions}

From 1956 to 1995, GDP per worker in Portugal relative to that of the United States increased from 0.26 to 0.53 . This reduction of the aggregate productivity gap with the United States was associated with a process of labor reallocation across sectors of production. In this paper, we build a general equilibrium model of the process of structural transformation.

\footnotetext{
${ }^{22}$ In addition, it is well known that distribution services represent a large portion of final-good prices in developed economies. For instance, the U.S. Department of Agriculture reports that out of every dollar spent on food in the U.S., eighty cents correspond to distribution and marketing services, while only twenty cents correspond to the producer price that farmers receive. As a result, low relative productivity in services may be partly responsible for the observed low relative productivity in agriculture. While our model does not explicitly account for the role of distribution services, the last counterfactual in the previous subsection suggests that if improvements in productivity in services go along with improvements in productivity in agriculture, then its aggregate productivity implications would be amplified.
} 
Using this model we are able to disentangle the role of sectoral labor productivity growth in the reduction of the aggregate productivity gap of Portugal relative to the United States. We find that relative labor productivity in manufacturing increased substantially and played an important role in this process. In turn, relative labor productivity in agriculture and services lagged behind. We show that the aggregate labor productivity performance in Portugal hinges on closing its productivity gap in services relative to the United States.

While our analysis is silent about the institutional and policy elements explaining the behavior of relative sectoral productivity, we conjecture that differences in the level of competition across sectors may be responsible for their diverse productivity performance. One possible source for differences in the level of competition across sectors is the degree of foreign competition. In particular, manufacturing goods are typically tradable while service goods (and, to a lesser extent, agricultural goods) are typically non-tradable. Therefore, foreign competition brought about by growth policies that promote trade tend to have a bigger impact on the structure of the manufacturing sector. In contrast, the institutional environment of the service sector cannot rely solely on foreign competition. Promoting labor productivity in the service sector requires policies that lower product-market regulation and barriers to entry that appear to be pervasive in this sector. To the extent that the service sector constitutes a large and increasing share of the economy, it is important to understand the sources of productivity growth in services and the policies that can promote it. We leave this relevant task for future research. 


\section{References}

[1] Banco de Portugal (2005). Séries Longas para a Economia Portuguesa.

[2] Caselli, F. and Colleman, W. J. (2001). "The U.S. Structural Transformation and Regional Convergence: A Reinterpretation," Journal of Political Economy, 109: pp. 584616.

[3] Cavalcanti, T. (2004) "Business Cycle and Level Accounting: The Case of Portugal," manuscript, Universidade Nova de Lisboa.

[4] Conference Board and Groningen Growth and Development Centre (2005), 10-Sector Database and Total Economy Database. <http://www.ggdc.net>.

[5] Cole, H., and Ohanian, L. (1999). "The Great Depression in the United States from a Neoclassical Perspective," Federal Reserve Bank of Minneapolis Quarterly Review, 23(1): pp. 2-24.

[6] Cooley, T. and E. C. Prescott (1995). "Economic Growth and Business Cycles," in Frontiers of Business Cycle Research, ed. T. Cooley. New Jersey: Princeton University Press.

[7] Duarte, M. and D. Restuccia (2006). "The Role of the Strutural Transformation in Aggregate Productivity," manuscript, University of Toronto.

[8] Echevarria, M. (1997). "Changes in Sectoral Composition Associated with Growth," International Economic Review, 38: pp. 431-52.

[9] Gollin, D., Parente, S., and Rogerson, R. (2002). "The Role of Agriculture in Development," American Economic Review Papers and Proceedings.

[10] Heston, A., R. Summers, and B. Atten. (2002). Penn World Table Version 6.1, Center for International Comparisons at the University of Pennsylvania (CICUP), $<$ http://pwt.econ.upenn.edu $>$.

[11] Kaldor, N. (1961). "Capital Accumulation and Economic Growth," in The Theory of Capital, ed. F.A. Kutz and D.C. Hague. New York: St. Martins. 
[12] Kehoe, T., and Prescott, E.C. (2002). "Great Depressions of the 20th Century," Review of Economic Dynamics 5: pp. 1-18.

[13] Kongsamut, P., S. Rebelo, and D. Xie (2001). "Beyond Balanced Growth," Review of Economic Studies 68, pp. 869-882.

[14] Kuznets, S. (1966). Modern Economic Growth, Yale University Press.

[15] Laitner, J. (2000). "Structural Change and Economic Growth," Review of Economic Studies, 67: pp. 545-61.

[16] Maddison, A. (1980). "Economic Growth and Structural Change in the Advanced Countries," in Western Economies in Transition, eds.: I. Leveson and W. Wheeler. London: Croom Helm.

[17] Ngai, L. R. and C. A. Pissarides (2004). "Structural Change in a Multi-Sector Model of Growth," American Economic Review, forthcoming.

[18] OECD Employment Database (2005). France.

[19] Prescott, E. C. (2004). "Why do Americans Work So Much More than Europeans?" manuscript, Arizona State University.

[20] Restuccia, D., Yang, D., and Zhu, X. (2005) "Agriculture and Aggregate Productivity: A Quantitative Cross-Country Analysis," manuscript, University of Toronto.

[21] Rogerson, R. (2005). "Structural Transformation and the Deterioriation of European Labor Market Outcomes," manuscript, Arizona State University.

[22] Silva, A. (2005). "Taxes and Labor Supply: Portugal, Europe, and the United States," manuscript, Universidade Nova de Lisboa.

[23] U.S. Census Bureau, Department of Commerce. Historical Statistics of the United States: Colonial Times to 1970 (Part I). Washington, DC: U.S. Government Printing Office, 1975. 


\section{A Data Sources and Definitions}

Aggregate Data We use annual data on aggregate GDP per worker for the United States and Portugal from Heston et al (2002), also known as the Penn World Tables Version 6.1 (PWT6.1).

Sectoral Data We adopt the following sectoral definitions: Agriculture comprises agriculture, forestry, and fishing; Industry comprises mining, manufacturing, public utilities, and construction; and Services includes wholesale and retail trade; transport and communication; finance, insurance, and real estate; community, social, and personal services; and government services. For the United States, we obtain data on employment by sector from 1869 to 1970 from the U.S. Census Bureau (1975), Historical Statistics of the United States. For the period 1956 - 1995, we obtain annual data for employment by sector from the OECD Employment Database (2005) and annual data for value added by sector from the Conference Board and Groningen Growth and Development Centre (2005), 10-Sector Database. For Portugal, we obtain annual data on employment by sector and value added by sector for the period 1956 - 1995 from Banco de Portugal (2005), Séries Longas para a Economia Portuguesa. For both the United States and Portugal, we compute labor productivity by sector as the ratio of value added to employment. However, it is not generally the case that the growth in aggregate labor productivity implied by the sectoral measures matches the growth in labor productivity from PWT6.1. Therefore, we adjust labor productivity in a sector by the ratio of the share of value added to the share of employment in that sector.

Smoothed Data All series (except the historical shares of employment in the United States) are smoothed by applying the Hodrick-Prescott filter to the log of each series with a smoothing parameter $\lambda=100$. 
Figure 1: Labor Productivity in Portugal Relative to the United States

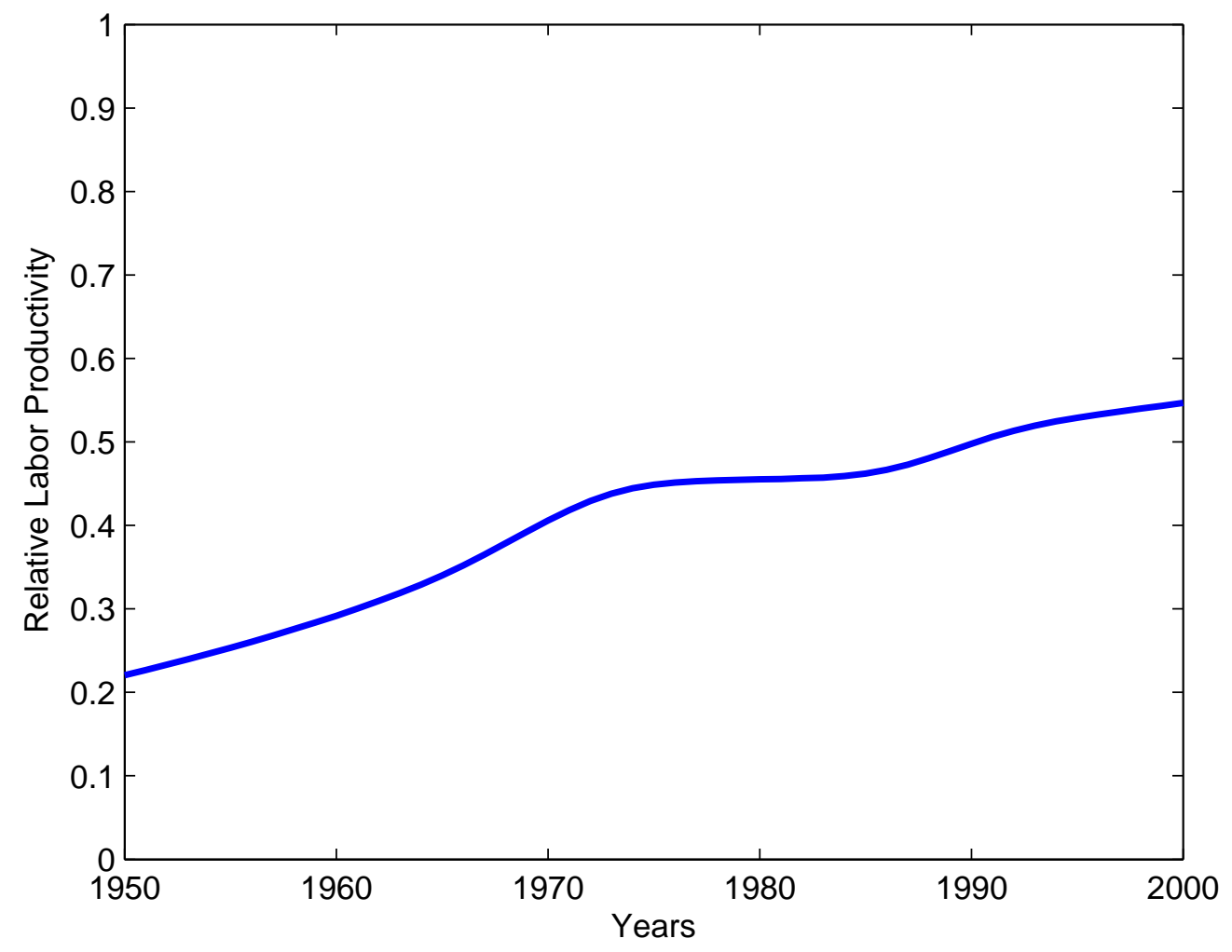

Note: Labor productivity is GDP per worker from PWT6.1. 
Figure 2: Share of Employment by Sector in the United States

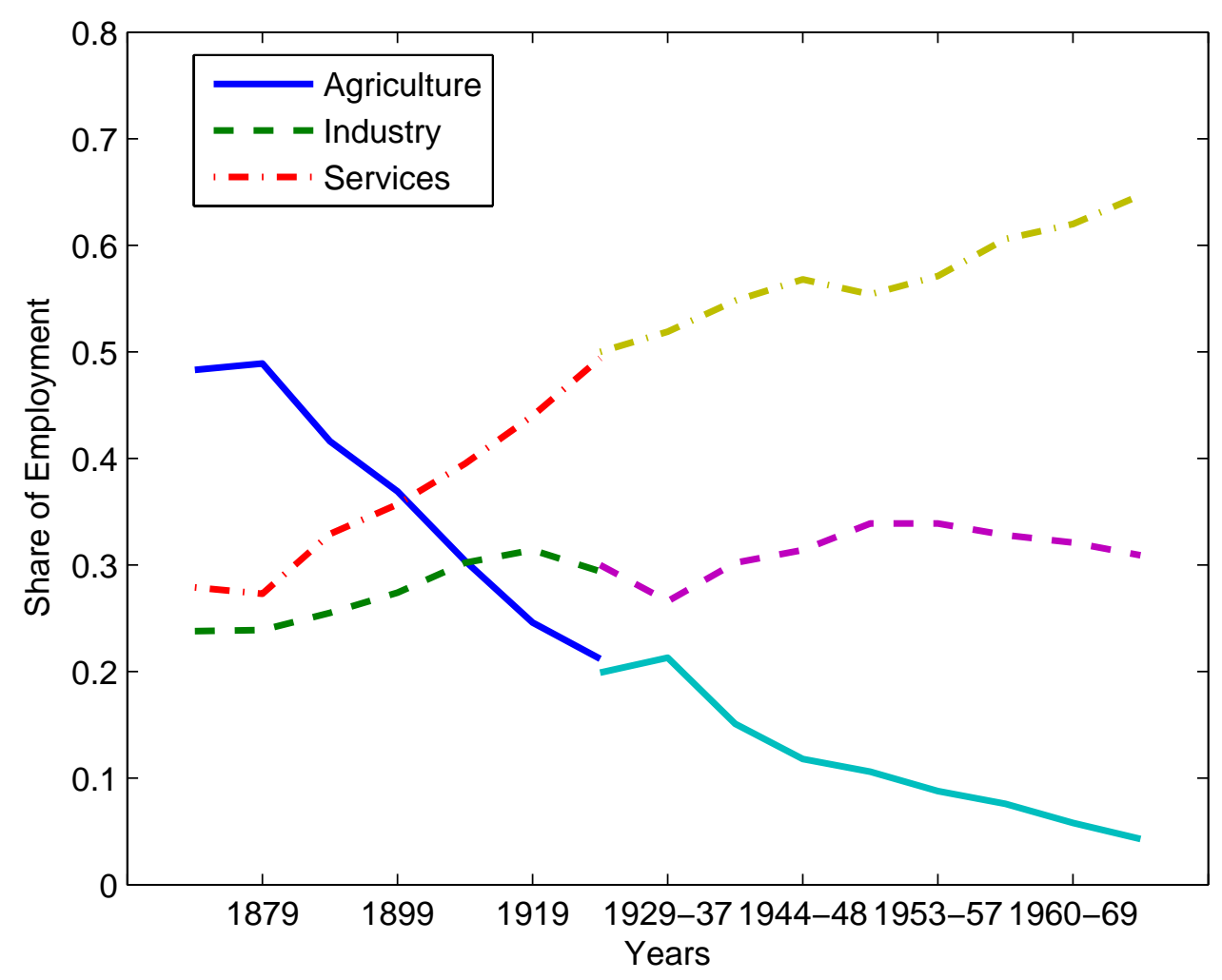

Note: The definition of employment is persons engaged in production by sector from the U.S. Census Bureau (1975). 
Figure 3: Share of Employment and Labor Productivity by Sector
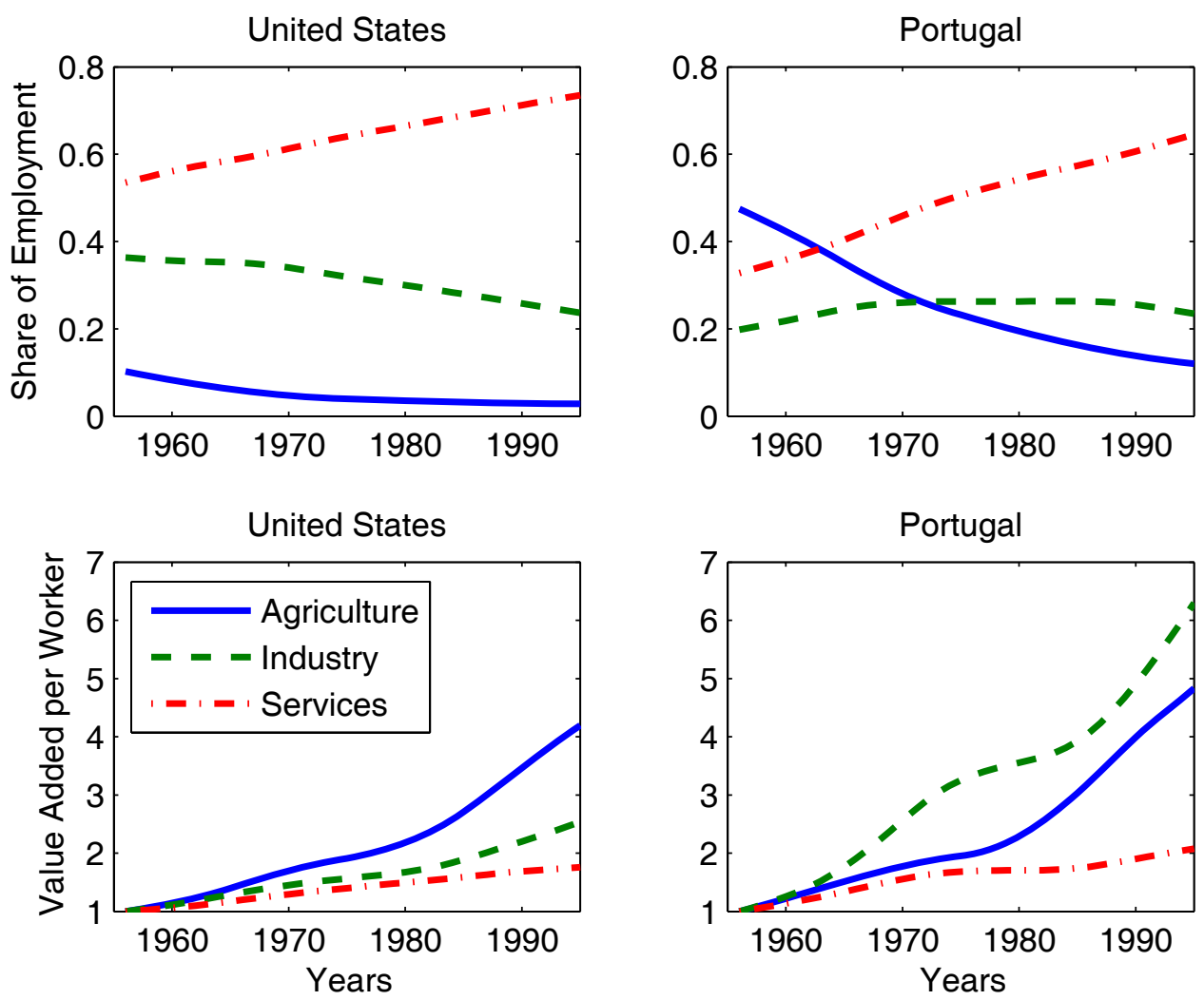

Note: The series for the United States are obtained from the OECD Employment Database (2005) and the Conference Board and Groningen Growth and Development Centre (2005) and the series for Portugal are obtained from the Bank of Portugal. See the Appendix for further details. 
Figure 4: The Structural Transformation in the United States

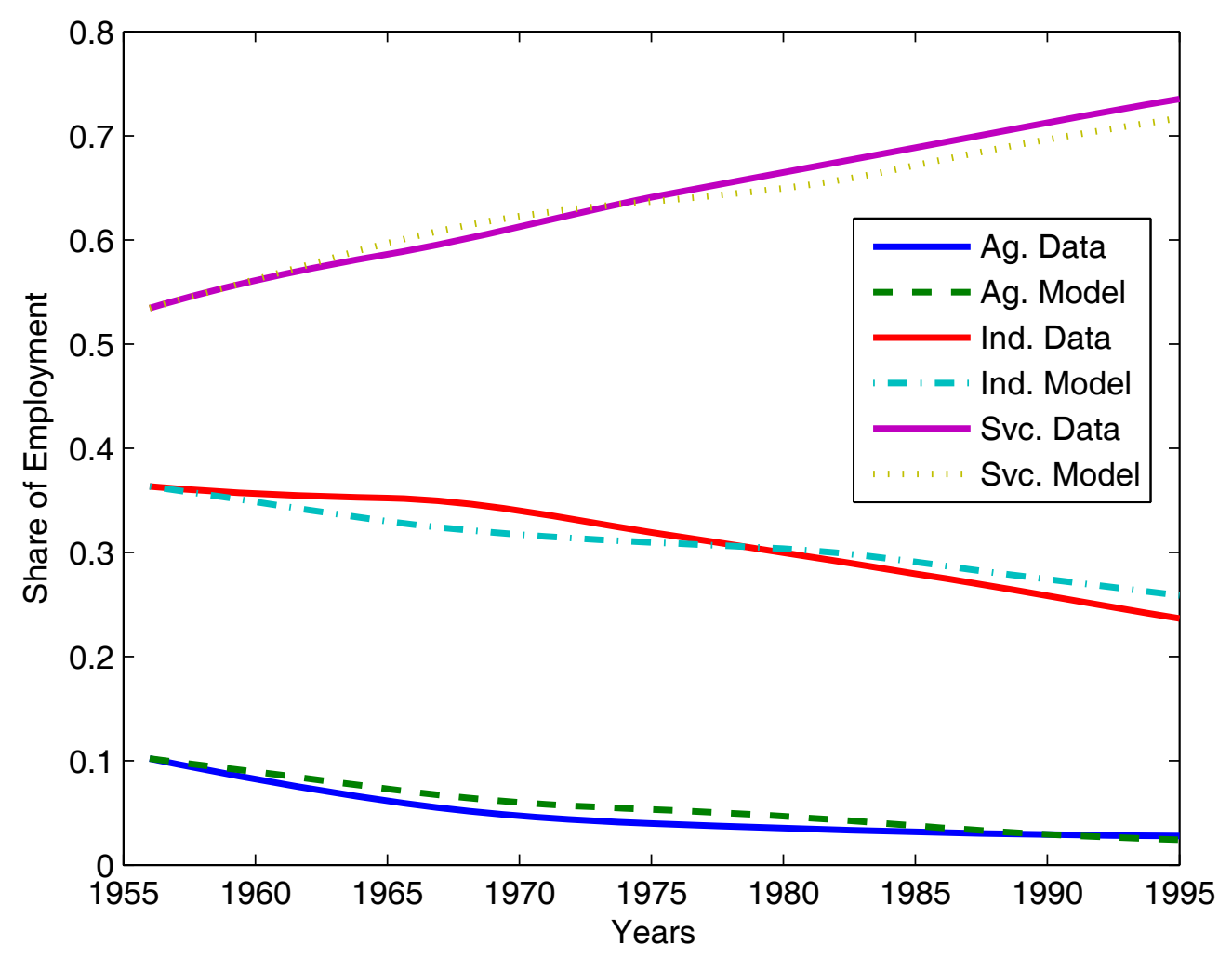


Figure 5: The Structural Transformation in Portugal
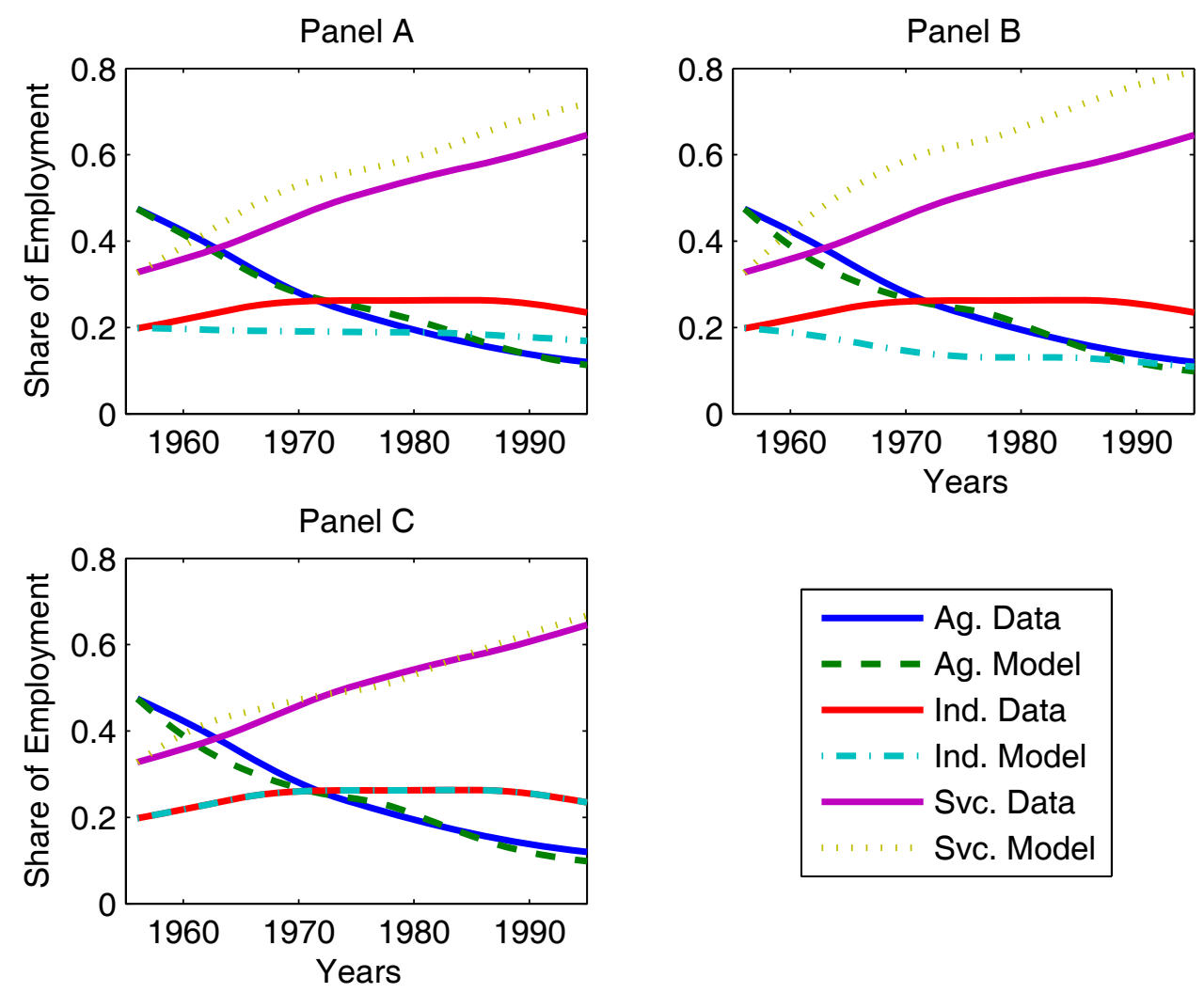
Figure 6: Sectoral Productivity (PT/US)

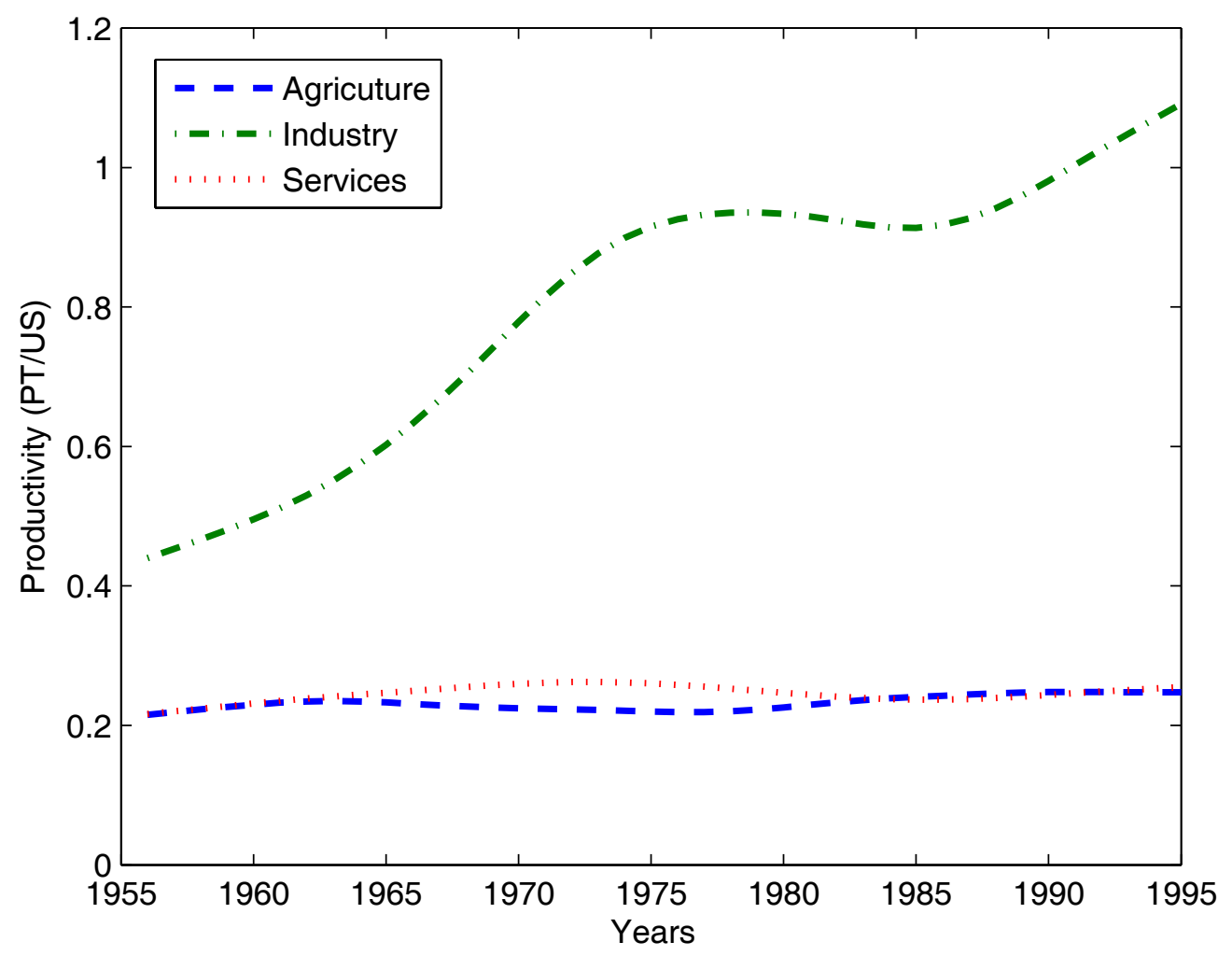


Figure 7: Counterfactuals on Sectoral Productivity

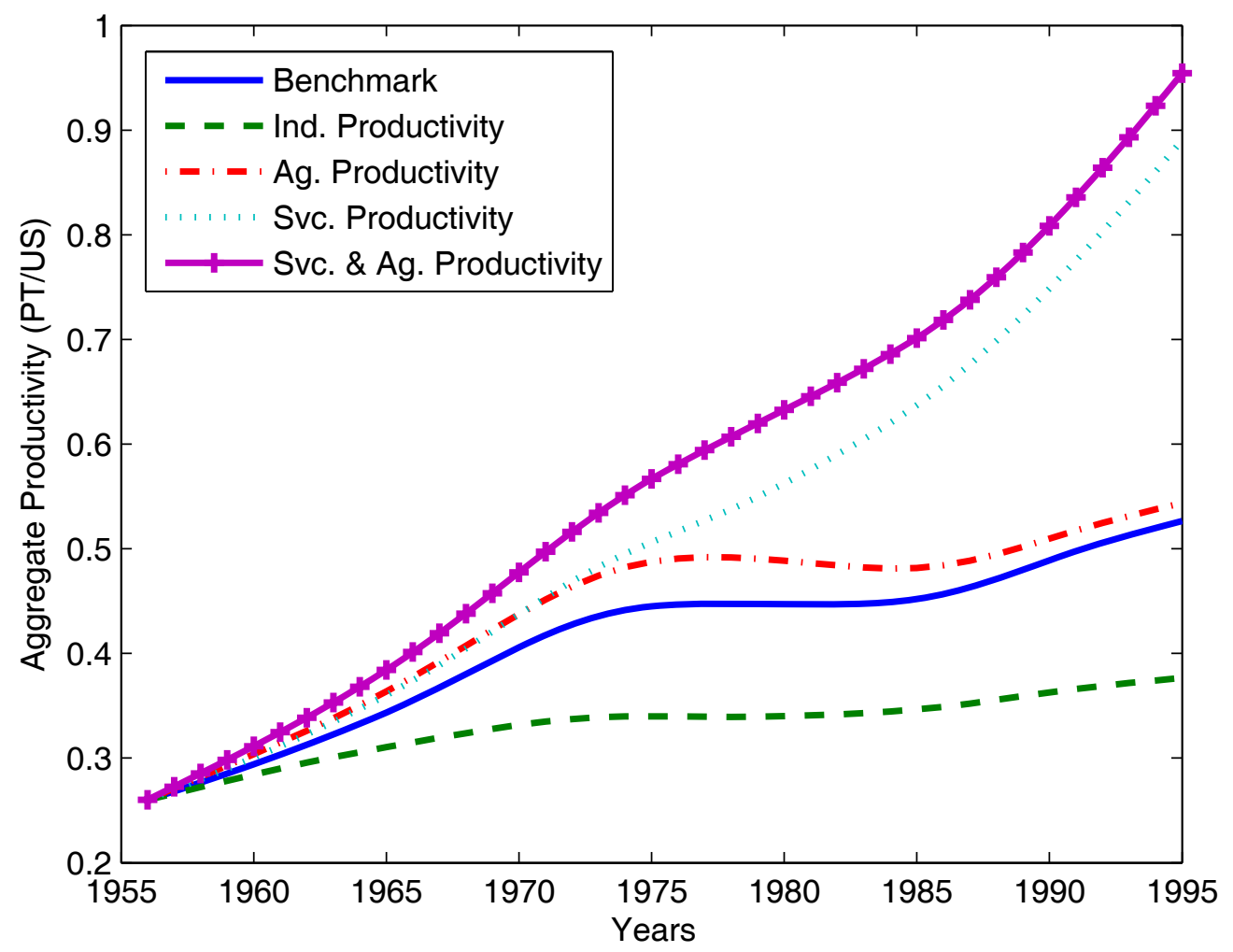

Note: These counterfactuals refer to the economy that reproduces the structural transformation in Portugal under alternative situations for sectoral productivity. Industry productivity considers labor productivity in manufacturing as in the United States. Agriculture productivity considers a change in relative productivity in agriculture from 0.22 to 0.97 . Service productivity considers a change in relative productivity in services from 0.22 to 0.89 . Agriculture and services productivity combines the previous two counterfactuals. (See Table 2 for more details and implications.) 